\title{
MAKNA DAN PERSEPSI MASYARAKAT \\ TERHADAP MANTRA SEMAR MESEM \\ DI DESA BURENG
}

\author{
KUMARA PASHA I. ${ }^{1}$, WAHAB SULHAN ${ }^{2}$, dan WAHYU SAHRUL H. ${ }^{3}$ \\ Prodi PBSI, FKIP, Universitas Muhammadiyah Malang \\ kumarapasha.i@gmail.com¹,wahabsulhan@gmail.com²,wahyuv743@gmail.com³
}

\begin{abstract}
Abstrak
Mantra merupakan susunan kata yang berunsur puisi seperti rima dan irama yang dianggap mengandung kekuatan gaib. Mantra biasanya diucapkan oleh dukun atau pawang untuk menandingi kekuatan gaib yang lain. Salah satunya mantra ajian semar mesem yang sering digunakan masyarakat untuk menarik perhatian dari lawan jenis. Mantra semar mesem ini biasanya diperoleh dari paranormal atau dukun. Tujuan penelitian ini adalah untuk mengetahui makna dan persepsi masyarakat Desa Bureng terhadap mantra ajian semar mesem di kehidupan sehari-hari. Sumber data yang digunakan yaitu mantra ajian semar mesem. Dalam penelitian ini digunakan metode penelitian kualitatif dengan menggunakan teori hermeneutika yang bertujuan untuk mengetahui sebuah makna dari mantra ajian semar mesem. Data yang dikumpulkan berupa mantra dan persepsi masyarakat beserta maknanya terhadap mantra ajian semar mesem. Sumber data yang digunakan dalam penelitian ini berupa mantra yang diperoleh dari salah seorang dukun Desa Bureng. Hasil dari penelitian ini adalah makna, fungsi, dan persepsi masyarakat Desa Bureng terhadap mantra ajian semar mesem yang banyak dari masyarakat desa tersebut belum mengetahui sebab akibat apabila mereka mengamalkannya..
\end{abstract}

Kata kunci: ajian semar mesem, makna, persepsi masyarakat

\begin{abstract}
Mantra is a wording with poetic elements such as rhymes and rhythms that are supposed to contain supernatural powers, spells are usually pronounced by shamans or handlers to match other magical powers. One of them is the semar mesa mantra that people often use to attract the attention of the opposite sex, the semar mantra this mesem is usually obtained from paranormal or dukun.Tujuan this research is to know the meaning and perception of the community of Bureng village against the spell ajian semar mesem in daily life. The source of data used is ajian semar mesem mantra.This research using qualitative research methods using the theory hermeneutics which aims to know a meaning of amantra ajian semar mesem. The data collected in the form of mantras and public perceptions along with their meanings to the semian ajir mantra mesem.Sumber of data used in this study in the form of mantras obtained from one shaman Bureng village. The results of this research is the meaning, function and perception of the community of Bureng Village against the spell of ajian semar mesem that many of the villagers do not know the cause and effect if they practice it.
\end{abstract}

Keywords: ajian semar mesem, meaning, perception society 


\section{PENDAHULUAN}

Sebagian masyarakat Indonesia masih mempercayai mantra sebagai bentuk ungkapan magis. Dikatakan "ungkapan magis" karena medium bahasanya bersifat khusus dan banyak menggunakan diksi yang bernuansa magis menurut Waluyo (dalam Ismawati, 2017:4).

Dalam masyarakat Indonesia diksi magis diyakini mampu menimbulkan sugesti yang besar bagi pengucap atau perapal mantra (Aswinarko, 2015:119). Jadi, sebagian besar masyarakat bureng memiliki kepercayaan terhadap hal-hal yang berbau magis seperti contohnya semar mesem.

Setiap daerah memiliki keunikan dan keragaman tersendiri. Begitu juga dengan Desa Bureng yang dikenal oleh sebagian orang sebagai daerah yang mempunyai kepercayaan mengenai halhal yang mistis. Banyak masyarakat Desa Bureng yang mengetahui nama mantra semar mesem. Akan tetapi, mereka tidak mengetahui makna, fungsi, dan sebab akibat yang ditimbulkan ketika mengamalkan mantra ini.

Mantra tersebut masih bertahan sampai saat ini yang dapat dimanfaatkan masyarakat dalam kehidupan sosial. Dari keempat magi yang menarik untuk dikaji yaitu mantra yang bermagi kuning. Mantra bermagi kuning tidak hanya dimiliki dukun, tetapi juga dapat digunakan dikalangan masyarakat (Intan, 2017:1). Mantra bermagi kuning dapat untuk mempengaruhi daya berpikir sesorang tanpa menggunakan jalan yang jahat, lebih tepatnya untuk mencari jodoh atau lebih terkenalnya masyarakat menyebut ilmu pengasihan

Kesenian, tradisi, dan tata cara hidup merupakan bagian dari kebudayaan (Dewi, 2014:2). Masyarakat Desa Bureng khusunya para sesepuh masih banyak yang mempercayai hal-hal yang berbau mistis dan masih ada yang mengamalkan mantra semar mesem ini. Namun, tidak semua masyarakat Desa Bureng mempercayai hal-hal tersebut. Masyarakat Desa Bureng yang percaya mengenai hal tersebut sebagian besar ialah masyarakat sesepuh desa. Istilah sesepuh untuk menyebut masyarakat tua yang berada di Desa Bureng yang masih mempercayai hal-hal mistis.

Masyarakat Desa Bureng sebagian besar beragama Islam, tetapi juga mempercayai hal-hal mistis. Masyarakat Desa Bureng beranggapan bahwa santet dan sejenisnya merupakan sebuah hal sebagai pawang untuk dirinya. Mereka tetap memandang dan bekerja keras menyikapi, mensiasati, dan melakukan negosiasi budaya dengan kekuatan- kekuatan yang hadir menghimpitnya (Maslikatin, 2012:153)

Semar mesem sendiri digambarkan dalam sebuah mantra santet ilmu pengasihan yang mempunyai simbol bermantra. Mantra semar mesem tersebut termasuk puisi lisan yang di mana dalam menggunakan lisan tersebut dilakukan dengan cara menghafal kata demi kata, salah satu komponen cukup penting yang menjadi keutuhan penyajian dalam memanfaatkan mantra adalah praktik upcara (Intan, 2017:5). Seseorang pengamal mantr semar mesem tersebut hanya dengan membaca dan melakukan ritual yang diberikan seorang paranormal kepada pengamal mantra semar mesem.

Berdasarkan uraian tersebut maka masalah yang diangkat dalam penelitian ini adalah bagaimana persepsi masyarakat Desa Bureng mengenai mantra Semar mesem, makna yang terkandung dalam mantra, dan fungsi serta sebab akibat ketika mengamalkan Semar mesem tersebut.

Penelitian mengenai mantra Semar mesem sudah pernah dilakukan dalam jurnal Intan (2017:7) 
yang membahas tentang simbolisme mantra Semar mesem terhadap kekuasaan di Banyuwangi, budaya lokal, dan identitas mantra hingga konvensi struktural. Kemudian dalam jurnal penelitiannya, dalam penelitian tersebut membahas tentang konvensi struktual, aspek kelisanan, dan fungsi mantra "Semar mesem". Akan tetapi, pada penelitian kali ini penulis meneliti tentang makna yang terkandung dan persepsi masyarakat Desa Bureng mengenai mantra "Semar mesem." Perlunya penelitian ini dilakukan yaitu untuk mengetahui persepsi masyarakat Desa Bureng mengenai mantra semar mesem. Masyarakat Desa Bureng sebagian besar banyak yang mengetahui akan familiarnya mantra semar mesem, tetapi tidak banyak yang mengerti makna, fungsi, sebab akibat, dan hubungan spritualisme dalam mantra semar mesem.

Pendekatan yang digunakan dalam penelitian ini adalah pendekatan reader respons karena pada penilitian ini menitik beratkan kepada makna mantra semar mesem yang familiar di Desa Bureng dan harus mewawancarai sesepuh desa untuk mengetahui siklus mantra semar mesem dan persepsi masyarakat Desa Bureng. Kemudian teori yang digunakan dalam penelitian ini adalah teori Hans Robert Jauss yang menjadi pemikir terkenal mengenai nasib pembaca dalam teori resepsi. Jauss dan Iser sama-sama memandang bahwa penafsiran bukan sebagai penemuan makna objektif atau makna yang tersembunyi dalam teks (Nuryatin 1998: 133). Kata kunci dari konsep yang diperkenalkan Jauss adalah rezeptions und wirkungsästhetik atau estetika tanggapan dan efek. Menurutnya, pembacalah yang menilai, menikmati, menafsirkan, dan memahami karya sastra. Pembaca dalam kondisi demikianlah yang mampu menentukan nasib dan peranannya dari segi sejarah sastra dan estetika. Resepsi sebuah karya dengan pemahaman dan penilaiannya tidak dapat diteliti lepas dari rangka sejarahnya seperti yang terwujud dalam horison harapan pembaca masing-masing. Baru dalam kaitannya dengan pembaca, karya sastra mendapat makna dan fungsinya

Setiap penelitian akan terkait dengan interpretasi. Interpretasi juga disebut hermeneutik. Artinya, pemaknaan terhadap fenomena. Setiap fenomena folklor memiliki makna tertentu dan makna tersebut baru akan terwujud jika telah ditafsirkan. Oleh karena itu, hermeneutik folklor juga dapat diartikan sebagai analisis tafsiriah folklor.

Pada dasarnya interpretasi dalam penelitian folklor menurut Ong (1985:147) meliputi dua aktivitas, yaitu (a) menyatakan sesuatu (reveals) dan (b) menyembunyikan sesuatu (conceals). Pernyataan jelas akan selalu ada dalam penafsiran sesuatu artinya fenomena di balik folklor. Adapun yang tersembunyi adalah pengertian. Hal ini berarti penafsiran folklor akan menyatakan sesuatu yang tersembunyi. Hal-hal yang tidak tersurat akan diungkap lewat interpretasi.

Menurut Ong (1985:148) pemaknan folklore pada akhirnya tidak lepas dari bagaimana membahasakan fenomena. Pembahasann ulang ini merupakan bentuk "to expres" (mengungkapkan), "to assert" (menegaskan) atau "to say" (menyatakan). Signifikasi teologis hermeneutika merupakan etimologi yang berbeda yang mencatat bahwa bentuk dari herme berasal dari bahasa Latin sermo, "to say" (menyatakan), dan bahasa Latin lainnya verbum, "word" (kata). Ini mengasumsikan bahwa utusan, dalam memberitakan kata, adalah "mengumumkan" dan "menyatakan" sesuatu; fungsinya tidak hanya untuk menjelaskan, tetapi untuk menyatakan (proclaim). Di dalam kesamaan petunjuk makna pertama ini terdapat perbedan tipis yang ditimbulkan dari, kata "to express" (mengungkapkan) yang bermakna "perkataan", tapi ia merupakan sebuah perkataan yang bagi dirinya sendiri merupakan sebuah interpretasi. 
Interpretasi seharusnya dilakukan secara hati-hati dan utuh sehingga peniliti folklor mampu menerka makna sesungguhnya. Peneliti folklor adalah seorang interpreter sehingga dia harus merekontruksi makna, dan bukan bertindak pasif. Konsep teori ini memang mendasarkan pada filosofi positivisme. Artinya, makna yang diperoleh didasarkan pada langkah teoritis tertentu. Kunci pokok interpretasi adalah "memahami" dan bukan "menjelaskan". Pemahaman folklor dapat ditelusuri melalui simbolsimbol yang tampak maupun tidak tampak.

Hermeneutik akan diasumsikan sebagai seni, ilmu, metode, atau pendekatan adalah sebuah pilihan. Tulisan ini memandang hermeneutik sebagai kajian sebuah metode dalam proses analisis sebuah karya yang mana makna yang terkandung dalam ajian semar mesem dapat dipahami dengan seksama. Konsep hermeneutic yang dipakai mengacu pada penyelarasan dari berbagai pandangan hermeneut-hermeneut, sebab pandangan para ahli terdahulu tentang hermeneutik memiliki benang merah berupa interpretasi atau pemahaman, kesadaran, simbol dan filsafat.

\section{METODE PENELITIAN}

Penelitian penelitian ini merupakan jenis penelitian kualitatif. Artinya data yang dikumpulkan bukan berupa angka-angka, melainkan data tersebut diperoleh melalui wawancara, catatan lapangan, dan dokumen pribadi. Pendekatan yang digunakan dalam penelitian ini adalah pendekatan reader respons karena pada penilitian ini menitikberatkan pada makna mantra semar mesem yang familiar di Desa Bureng dan harus mewawancarai salah sesepuh desa untuk mengetahui siklus mantra semar mesem dan persepsi masyarakat Desa Bureng.

\section{Data dan Sumber Data}

Sumber data dalam penelitian ini diperoleh dengan wawancara secara langsung dengan salah seorang dukun yang berada di Desa Bureng. Data yang diperoleh nantinya akan dianalisis makna serta persepsi masyarakat sekitar Desa Bureng apabila mereka mengamalkannya.

\section{Teknik Pengumpulan Data}

Teknik pengumpulan data yang digunakan yaitu dengan cara wawancara kepada salah satu dukun yang berada di Desa Bureng dengan cara mengajukan beberapa pertanyaan terkait makna ajian semar mesem. Selanjutnya peneliti mengobservasi tentang persepsi masyarakat yang menggunakan ajian semar mesem.

\section{Teknik Analisis Data}

Adapun teknik yang digunakan dalam menganalisis mantra ajian semar mesem adalah analisis isi. Teknik analisis isi mampu mendreskipsikan atau menggambarkan hasil analisis fungsi dan makna dalam mantra ajian semar mesem.

Penelitian dengan metode analisis isi digunakan untuk menelaah isi dari suatu dokumen. Dalam penelitian ini dokumen yang dimaksud adalah mantra ajian semar mesem. Untuk mengecek kebsahan data yaitu peneliti ikut serta dalam proses wawancara dengan dukun yang telah ditentukan serta peneliti merekam atau mencatat hasil wawancara dengan seksama. 


\section{HASIL DAN PEMBAHASAN}

Mantra adalah sekumpulan kata yang dipercaya bisa merubah keadaan spiritual. Dari hal tersebut sehingga muncul mantra ajian semar mesem yang memiliki kegunaan untuk memikat lawan jenis yang memiliki makna tertentu.

\section{Makna Mantra Ajian Semar Mesem}

"Ingsun amateek ajiku si semar mesem, mutmutanku inten, cahyane manjingono pilingananku, kiwo tengen sing nyawang ke giwang, opo maneh sing nyawang kang kumantil tumancep ing sanubariku yo iku si jabang bayine, welas asih marang badan slirahku, songko kersaning Allah." Arti kata tersebut dalam bahasa Indonesia adalah aku merapal mantraku si semar mesem Mutmutaku Intan, cahayaku terbit dari kening kiri kanan yang melihat kebimbang apalagi jika yang melihat yang tertancap melekat dalam relung sanubariku yaitu si jabang bayi ... sudah pasti akan datang belas kasih kepada jiwa ragaku atas kehendak Allah.

Adapun makna yang terkandung dalam mantra ajian semar mesem ini yaitu untuk mengeluarkan ajian semar mesem untuk menarik perhatian kepada seseorang yang dia sukai agar dia yang dia sukai bisa jatuh hati kepadanya. Selain itu, menurut orang yang diwawancarai mantra ini juga bisa memperlihatkan aura positif dari orang yang menggunakannya.

\section{PENUTUP}

Berdasarkan hasil penelitian dan informasi masyarakat dapat disimpulkan bahwa setiap mantra yang disakralkan oleh masyarakat setempat memiliki makna dan fungsi tersendiri, sesuai dengan apa yang diyakini masyarakat tersebut. Dengan begitu setiap orang memiliki pendapat yang berbeda dalam menanggapi mantra tersebut.

\section{DAFTAR PUSTAKA}

Aswinarko, A. (2015). Kajian Deskriptif Wacana Mantra. Deiksis, 5(02), 119-128.

Dewi, Ewinda Sukma. 2014. Fungsi Sosial Tari Jaran Goyang Aji Kembang Pada Masyarakat Using Kabupaten Banyuwangi. Universitas Negeri Yogyakarta. Skripsi.

Endraswara, Suwardi. 2009. Metodologi Penelitian Folklor. Yogyakarta: Media Pressindo.

Intan, Tania. 2017. Studi Terhadap Resepsi Pembaca Perempuan Pada Novel Romantis

Berbahasa Indonesia dan Perancis dengan Konsep Reading TheRomance dari Janice Radway. 
Universitas Padjadjaran. Disertasi.

Ismawati, Esti. 2017. Mantra Bumi Karya Arpinus Salam Sebagai Bahan Ajar Apresiasi Sasra. 67681

Maslikatin, Titik. 2012. Kerudung Santet Gandrung Dialektika Sastra dan Tradisi Sub-Kultur Masyarakat Osing-Banyuwangi. Staf Pengajar Fakultas Sastra Universitas Jember. Prossiding.

Nuryatin, Agus. Resepsi Estetis Pembaca Atas Sri Sumarah dan Bawuk Karya Umar Kayam. Dalam Jurnal Lingua Artistik, 1998, 2: 130-141.

Ong, Roberto K. The Interpretation of Dreams in Ancient China. Brockmayer.

Wulandari, Intan. "Simbolisme Mantra Semar mesem Terhadap Kekuasaan Di Banyuwangi." 